\title{
Anthropogenic impacts on hyperbenthos in the coastal waters of Sishili Bay, Yellow Sea*
}

\author{
LI Baoquan (李宝泉) ${ }^{1, * *}$, John K. KEESING ${ }^{2}$, LIU Dongyan (刘东艳) ${ }^{1}$, \\ HAN Qingxi (韩庆喜) ${ }^{1}$, WANG Yujue (王玉玨) ${ }^{1}$, DONG Zhijun (董志军) ${ }^{1}$, CHEN Qiao (陈桥) ${ }^{3}$ \\ ${ }^{I}$ Key laboratory of Coastal Zone Environmental Processes, CAS; Shandong Provincial Key laboratory of Coastal Zone \\ Environmental Processes; Yantai Institute of Coastal Zone Research, Chinese Academy of Sciences, Yantai 264003, China \\ ${ }^{2}$ CSIRO Marine and Atmospheric Research, Private Bag 5, Wembley 6913, Australia \\ ${ }^{3}$ College of Geological Science \& Engineering, Shandong University of Science and Technology, Qingdao 266590, China
}

Received Aug. 10, 2012; accepted in principle Oct. 19, 2012; accepted for publication Nov. 1, 2012

(C) Chinese Society for Oceanology and Limnology, Science Press, and Springer-Verlag Berlin Heidelberg 2013

\begin{abstract}
A survey on the hyperbenthic communities was carried out in the coastal waters of Sishili Bay in the Yellow Sea in July 2009, to investigate the impact of putative anthropogenic activities related to the presence of a sewage outfall, a harbor and an aquaculture site on the benthic ecosystem. An Agassiz net trawl was used to collect hyperbenthos at 10 sampling stations. Species, diversity, abundance, and biomass were analyzed against water sample data and historical data obtained from records from nearby Yantai City. Fifty-two species were identified in the region, of which Crustacea were the most abundant taxon, followed by Echinodermata. Dominant species included five crustaceans, two echinoderms, one mollusk and one fish species. The results of a BIOENV analysis show that the concentrations of $\mathrm{NO}_{3}-\mathrm{N}$ and Chl- $a$ were slightly positively correlated with hyperbenthic community structure, while other factors were negatively correlated, including sediment grain size and the percentage of TN and TOC in sediment. AbundanceBiomass Comparison (ABC method) curves indicate that the hyperbenthos in Sishili Bay had been disturbed by putative sources of human activities. Eight out of 10 stations were classified as "moderately perturbed" to "perturbed".
\end{abstract}

Keyword: hyperbenthos; suprabenthos; biodiversity; Northern Yellow Sea; anthropogenic activity

\section{INTRODUCTION}

Coastal ecosystems are becoming increasingly degraded because of overly intensive industrial use and waste discharge (Ferrara et al., 1991; McGlathery et al., 2007). While there have been many published accounts of the consequences of these perturbations around the world, there are few recorded studies from China where a large population coupled with recent rapid economic growth have had predictably deleterious impacts on coastal areas.

The Yellow Sea is one of the most important fishing grounds in Chinese waters; however, these fisheries are in decline because of the ecosystem degradation of the Yellow Sea, which has been particularly severe in recent years (Tang, 2004). Since the 1980s, intensive human activities, such as aquaculture, sewage discharge and coastal engineering, have significantly affected the environments of the coastal areas of the Yellow Sea and degraded the marine ecosystem (Wang et al., 1995; Tang, 2004; Liu et al., 2009). Sishili Bay (SB), located in the northern Yellow Sea, is an important harbor in Shandong Province, China, and is used for marine aquaculture, suppling local seafood markets. Over the last two decades, the rapid development of the surrounding Yantai City has put a great stress on the marine ecosystem of SB because of associated increases in population, aquaculture, wastewater discharge, and cargo throughput (Yantai Statistics Bureau, 2001-

\footnotetext{
* Supported by the Knowledge Innovation Program of Chinese Academy of Sciences (No. KZCX2-YW-Q07-04), the National Natural Science Foundation of China (No. NSFC41061130543), and the Science and Technology Planning Project of Shandong Province (No. 2011GGF01003). ** Corresponding author: bqli@yic.ac.cn
} 
2009). Large quantities of nutrients from sewage discharge and aquaculture have been added to SB, including 150 tons of TP (total phosphorus) and 1910 tons of TN (total nitrogen) every year (Liu et al., 2006). The increased occurrence of red tides and jellyfish blooms are symptoms of the deterioration of the marine ecosystem (Dong et al., 2010).

The physical processes that control the temporal and spatial variation of circulation within SB and exchange between the bay and the Yellow Sea are driven mostly by wind and tides. Semidiurnal and irregular diurnal tides are the dominant tidal components and are responsible for most of the variation in currents and kinetic energy inside the bay. The maximum tidal current is about $40 \mathrm{~cm} / \mathrm{s}$ along the periphery of the bay, while the tidal current inside the bay is relatively weak (about $10 \mathrm{~cm} / \mathrm{s}$ ) (Zhang and Dong, 1990). The mixed tidal pattern can create turbulent mixing, which results in the vertical homogenization of biological variable profiles. During summer time, the entire bay is dominated by a southeasterly wind and the wind-induced currents can significantly influence bay-scale water transport near the surface, especially in the inner bay where the residual tidal current is weak. Thus, there is significant mixing and weak stratification within SB, which affects how pollution in one part of SB affects another.

Macrobenthic organisms play important roles in ecosystem processes including nutrient cycling, trophodynamics, metabolizing pollutants, dispersion and burial (Snelgrove, 1998). Because macrobenthic species are relatively sedentary, their species composition and abundance can be used as a biological indicator of ecosystem health and to reflect changes in the marine environment, such as the deterioration of water and sediment conditions (Pearson and Rosenberg, 1978; Lu, 2005). The hyperbenthos (or suprabenthos) consists of marine macrobenthic animals that live in the water layer near to the bottom of the sea and are distinctly different from other macrobenthic groups that include attached benthic, infaunal, and planktonic species. Commercial exploitation is often focused on the hyperbenthos (e.g. shrimps, crabs, demersal fish and some mollusks such as scallops) (Mees and Jones, 1997), and these animals fulfill important ecosystem functions including biogenic modification of the benthos (Brandt, 1993, 1995). Because of their importance as a food resource, hyperbenthic assemblages have been extensively studied (Mees and Jones, 1997; San et al., 1997, 2007; Ye et al., 2010). Several studies on macrobenthic fauna have been conducted in SB $(\mathrm{Wu}$ and Zhang, 1994; Wang et al., 1995) including on the impacts of dumping areas for dredged materials (Ji et al., 2003; Liu et al., 2010). However, these studies have not examined the relationship between macrobenthic communities and environmental variables and have not specifically considered the hyperbenthos.

The aim of this study was to provide original data on the species composition, abundance, biomass, and distribution of hyperbenthic assemblages in SB, and to detect possible anthropogenic impacts. The study provides baseline for further ecological research and environmental assessments of hyperbenthic communities in Northeast China as rapid industrialization and intensification of coastal uses continue.

\section{METHOD}

\subsection{Sampling stations}

The hyperbenthos of SB was studied at 10 stations; these were located in four zones, which have been affected by different kinds of anthropogenic disturbance. The 10 sampling stations were located in the coastal waters of SB within the area $37^{\circ} 32^{\prime}-$ $37^{\circ} 40^{\prime} \mathrm{N}$ and $121^{\circ} 21^{\prime}-121^{\circ} 37^{\prime} \mathrm{E}$. Stations were grouped in the following zones: zone A: sewage outfall (A1, A2, A3); zone B: harbor areas (B1, B2, $\mathrm{B} 3)$; zone $\mathrm{C}$ : aquaculture area $(\mathrm{C} 1)$ and zone $\mathrm{D}$ : outer areas (D1, D2, D3) (Fig.1, Table 1).

\subsection{Sampling strategy}

An Agassiz trawl $(1.5 \mathrm{~m} \times 0.5 \mathrm{~m}$, with a mesh size of $2 \mathrm{~cm}$ at the "mouth" and $0.7 \mathrm{~cm}$ at the cod end) was commonly used to collect macrobenthos for quantitative and qualitative analysis in July 2009. The sled was towed on the sea bottom for 10-30 min at about $2.5 \mathrm{knots}$ (about $5 \mathrm{~km} / \mathrm{h}$ ). Bottom haul length was estimated using the GPS-derived position at the beginning and at the end of each tow. Abundance and biomass were calculated from haul lengths and the area of the sea floor swept by the sled. The material sampled with the sled was preserved in $80 \%$ alcohol or frozen and then transported to a laboratory where it was identified to the lowest possible taxonomic level (mostly to species), counted and weighed using a $0.001 \mathrm{~g}$ precision electric balance to obtain the abundance and wet weight. The presence of multiple raft cables and other scallop aquaculture facilities in the water and on the bottom in the aquaculture zone 
Table 1 Haul lengths and areas of sampling stations in SB

\begin{tabular}{|c|c|c|c|c|c|c|c|}
\hline \multirow{2}{*}{$\begin{array}{c}\text { Stations/ } \\
\text { Areas }\end{array}$} & \multicolumn{2}{|c|}{ Initial position } & \multicolumn{2}{|c|}{ Final position } & \multirow{2}{*}{ Length of haul (m) } & \multirow{2}{*}{ Area of haul $\left(\mathrm{m}^{2}\right)$} & \multirow{2}{*}{ Depth (m) } \\
\hline & Latitude & Longitude & Latitude & Longitude & & & \\
\hline A1 & $37^{\circ} 38^{\prime} 31.2^{\prime \prime}$ & $121^{\circ} 21^{\prime} 56.7^{\prime \prime}$ & $37^{\circ} 38^{\prime} 44.0^{\prime \prime}$ & $121^{\circ} 22^{\prime} 02.8^{\prime \prime}$ & 432 & 648 & 21.4 \\
\hline A2 & $37^{\circ} 38^{\prime} 7.68^{\prime \prime}$ & $121^{\circ} 22^{\prime} 44.34^{\prime \prime}$ & $37^{\circ} 37^{\prime} 55.8^{\prime \prime}$ & $121^{\circ} 23^{\prime} 44.76^{\prime \prime}$ & 1523 & 2284.5 & 17.9 \\
\hline A3 & $37^{\circ} 37^{\prime} 51.06^{\prime \prime}$ & $121^{\circ} 24^{\prime} 17.64^{\prime \prime}$ & $37^{\circ} 37^{\prime} 42.42$ & $121^{\circ} 25^{\prime} 23.04$ & 1622 & 2433 & 18.7 \\
\hline B1 & $37^{\circ} 35^{\prime} 6.3^{\prime \prime}$ & $121^{\circ} 25^{\prime} 55.2^{\prime \prime}$ & $37^{\circ} 34^{\prime} 46.92^{\prime \prime}$ & $121^{\circ} 25^{\prime} 38.76^{\prime \prime}$ & 721 & 1081.5 & 10.7 \\
\hline B2 & $37^{\circ} 35^{\prime} 33.2^{\prime \prime}$ & $121^{\circ} 26^{\prime} 32.1^{\prime \prime}$ & $37^{\circ} 35^{\prime} 04.7^{\prime \prime}$ & $121^{\circ} 25^{\prime} 56.9^{\prime \prime}$ & 1232 & 1848 & 11.0 \\
\hline B3 & $37^{\circ} 33^{\prime} 27.0^{\prime \prime}$ & $121^{\circ} 26^{\prime} 29.4^{\prime \prime}$ & $37^{\circ} 33^{\prime} 28.8^{\prime \prime}$ & $121^{\circ} 25^{\prime} 43.7^{\prime \prime}$ & 1120 & 1680 & 8.5 \\
\hline $\mathrm{C} 1$ & $37^{\circ} 32^{\prime} 06.2^{\prime \prime}$ & $121^{\circ} 34^{\prime} 19.7^{\prime \prime}$ & $37^{\circ} 32^{\prime} 19.6^{\prime \prime}$ & $121^{\circ} 34^{\prime} 46.5^{\prime \prime}$ & 776 & 1164 & 11.2 \\
\hline D1 & $37^{\circ} 36^{\prime} 40^{\prime \prime}$ & $121^{\circ} 31^{\prime} 33.6^{\prime \prime}$ & $37^{\circ} 36^{\prime} 26.1^{\prime \prime}$ & $121^{\circ} 30^{\prime} 34.6^{\prime \prime}$ & 1506 & 2259 & 10.5 \\
\hline D2 & $37^{\circ} 39^{\prime} 05.9^{\prime \prime}$ & $121^{\circ} 35^{\prime} 44.9^{\prime \prime}$ & $37^{\circ} 39^{\prime} 07.6^{\prime \prime}$ & $121^{\circ} 34^{\prime} 57.5^{\prime \prime}$ & 1160 & 1740 & 10.4 \\
\hline D3 & $37^{\circ} 36^{\prime} 15.6^{\prime \prime}$ & $121^{\circ} 36^{\prime} 07.8^{\prime \prime}$ & $37^{\circ} 37^{\prime} 07.1^{\prime \prime}$ & $121^{\circ} 36^{\prime} 05.8^{\prime \prime}$ & 1592 & 2388 & 10.2 \\
\hline
\end{tabular}

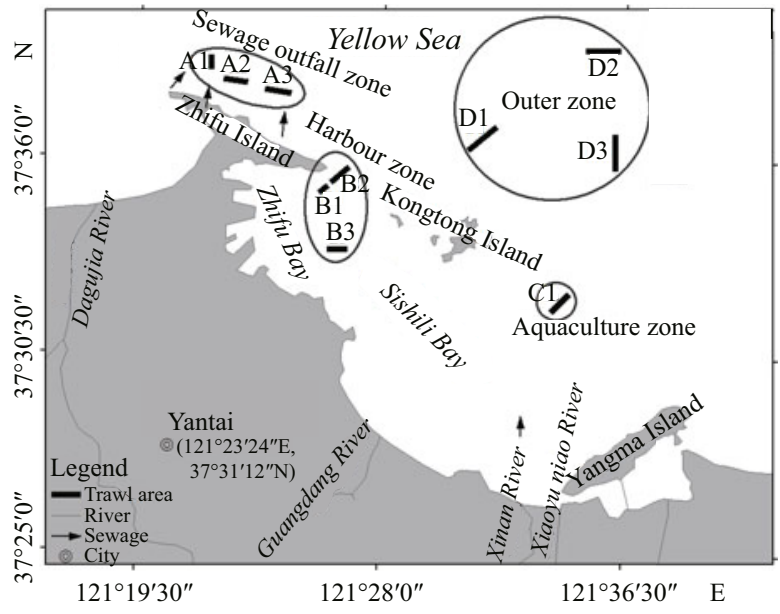

Fig.1 Study area and locations of sampling stations in SB

(C), which baffled the trawl, meant that only one station $(\mathrm{C} 1)$ could be surveyed successfully in this area.

\subsection{Environmental variables}

Two separate replicate water samples were collected by Niskin bottle and two sediment samples were collected by a modified $0.05 \mathrm{~m}^{2}$ Gray-O' Hara box-corer at eight stations (A1, A2, A3, B2, B3, C1, D1, D3) on another survey in July 2009. The environmental factors included water depth, temperature, salinity, nutrients $\left(\mathrm{NH}_{4}-\mathrm{N}, \mathrm{NO}_{2}-\mathrm{N}\right.$, $\left.\mathrm{NO}_{3}-\mathrm{N}, \mathrm{TN}, \mathrm{SiO}_{3}-\mathrm{Si}, \mathrm{PO}_{4}-\mathrm{P}\right), \mathrm{pH}, \mathrm{Chl}-a$ in the bottom water, and sediment grain size, and concentration of TN and TOC in the surface sediment $(0-5 \mathrm{~cm})$ were measured at the same stations. The depth, temperature, salinity and Chl- $a$ were measured with an YSI Environmental Monitoring System (made by YSI
Incorporated Yellow Springs Ohio 54387 USA, mode: $600 \mathrm{QS}-\mathrm{M}-\mathrm{O}$ ); the nutrients were measured by the nutrient auto-analyzer using gas-segmented continuous flow analysis (AutoAnalyzer 3, Bran Luebbe, Germany). Sediment grain size was measured using Mastersizer 2000 Laser Particle Sizer (Malvern Instruments Limited, UK), which was capable of measuring grain sizes from 0.02 to $2000 \mu \mathrm{m}$, with a relative error of less than $1 \%$. The percentages of total nitrogen (TN) and total organic carbon (TOC) in the surface sediments were measured by CNS analyzer (Vario MACRO CN).

\subsection{Statistical analysis}

Plymouth routines in multivariate ecological research (PRIMER 6.0) software were used for statistical analyses (Clark and Gorley, 2001). Univariate diversity indices were calculated from species abundance data. Abundance data were "square root" transformed to calculate intersample similarities by Bray-Curtis coefficients. Non-metric multidimensional scaling (MDS) and hierarchical cluster analysis (CLUSTER) were used to analyze the macrobenthic community characteristics. Analysis of similarities (ANOSIM) and Similarity/distance percentages (SIMPER) were used to test for differences between groups of samples and to examine the contribution of each variable to average resemblances between sample groups, respectively. $\mathrm{K}$-dominance and $\mathrm{ABC}$ curves were constructed to examine the ecological characteristics of hyperbenthic assemblages. Correlation coefficients (Spearman) between water quality factors and the community structure of the hyperbenthos were analyzed by Biota- 
Table 2 The concentrations of nutrients in bottom water of SB

\begin{tabular}{|c|c|c|c|c|c|c|c|}
\hline Stations & $\mathrm{NO}_{2}-\mathrm{N}(\mu \mathrm{mol} / \mathrm{L})$ & $\mathrm{NO}_{3}-\mathrm{N}(\mu \mathrm{mol} / \mathrm{L})$ & $\mathrm{NH}_{4}-\mathrm{N}(\mu \mathrm{mol} / \mathrm{L})$ & $\mathrm{TDN}(\mu \mathrm{mol} / \mathrm{L})$ & $\mathrm{PO}_{4}-\mathrm{P}(\mu \mathrm{mol} / \mathrm{L})$ & $\mathrm{SiO}_{3}-\mathrm{Si}(\mu \mathrm{mol} / \mathrm{L})$ & Chl- $a(\mu \mathrm{g} / \mathrm{L})$ \\
\hline A1 & 0.3 & 1.0 & 0.3 & 29.5 & 0.5 & 2.3 & 1.0 \\
\hline A2 & 0.4 & 1.1 & 0.7 & 39.3 & 0.2 & 2.4 & 1.8 \\
\hline A3 & 0.2 & 1.5 & 0.1 & 35.7 & 0.1 & 2.1 & 1.9 \\
\hline B2 & 0.3 & 2.1 & 0.2 & 37.5 & 0.1 & 1.7 & 3.1 \\
\hline B3 & 0.5 & 2.4 & 1.0 & 30.0 & 0.2 & 1.7 & 1.6 \\
\hline $\mathrm{C} 1$ & 0.2 & 0.6 & 1.1 & 29.8 & 0.4 & 1.7 & 2.4 \\
\hline D1 & 0.2 & 0.7 & 0.4 & 35.9 & 0.2 & 2.2 & 1.2 \\
\hline D3 & 0.2 & 0.8 & 0.9 & 36.9 & 0.2 & 2.1 & 1.2 \\
\hline
\end{tabular}

Environment Stepwise Analysis (BIOENV/ BVSTEP). The biological properties included the total biomass $(B)$, the abundance $(A)$, the number of species $(S)$, the Shannon-Wiener diversity index $\left(H^{\prime}\right)$, the Margalef richness index $(d)$, and the dominant index $(Y)$. In the statistical analysis, the unit of biomass was $\mathrm{g} / \mathrm{ha}$ and abundance was individuals per ha (inds./ha). The dominant index of species was calculated using the following formula (Chen and $\mathrm{Xu}$, 1995):

$$
Y=\left(n_{i} / N\right) f_{i}
$$

where $N$ is the total abundance of all the stations; $n_{i}$ is the abundance of the species $i$ at all the stations; and $f_{i}$ is the occurrence frequency of species $i$ at all the stations.

With the exception of the analysis of community characteristics, rare or opportunistic species were excluded from the cluster analysis to reduce the influence of rare or opportunistic species when comparing sites and relationships with environmental variables. Species that accounted for less than $1 \%$ of the total abundance of the research region were deleted from the analysis unless the species made up more than $3 \%$ of the abundance at any of the stations in the trawl areas.

\section{RESULT}

\subsection{Analysis of environmental variables}

3.1.1 Nutrients and Chl- $a$ in bottom water and concentrations of TN and TOC in the sediment

Chl $-a$ concentrations at the study stations varied from 1.0 to $3.1 \mu \mathrm{g} / \mathrm{L}$ with a mean value of $1.7 \mu \mathrm{g} / \mathrm{L}$ (Table 2). High Chl- $a$ concentrations were found inside SB (zone B and zone $\mathrm{C}$ particularly at station B2), with the highest values of $3.1 \mu \mathrm{g} / \mathrm{L}$; while outside SB (zone $\mathrm{A}$ and zone D) concentrations were relatively low.
Obvious anthropogenic input of $\mathrm{NO}_{3}-\mathrm{N}$ was found at Station $\mathrm{B} 3$, which resulted in the high concentrations of $\mathrm{NO}_{3}-\mathrm{N}(2.4 \mu \mathrm{mol} / \mathrm{L})$ and $\mathrm{NO}_{2}-\mathrm{N}(0.5 \mu \mathrm{mol} / \mathrm{L})$ in this area compared with stations outside of the bay and in the aquaculture area. The effect of aquaculture on $\mathrm{NH}_{4}-\mathrm{N}$ was obvious during the study period, with high $\mathrm{NH}_{4}-\mathrm{N}$ concentrations in the southeast and low in the northwest with the highest value of $1.1 \mu \mathrm{mol} / \mathrm{L}$ at station $\mathrm{C} 1$ in the aquaculture area.

Distributions of TN and TOC in sediments in the trawling area both showed relatively higher values outside SB in zones A and D $(0.56 \%$ TOC and $0.07 \%$ $\mathrm{TN})$ than inside SB in zones B and C $(0.36 \%$ TOC and $0.04 \% \mathrm{TN}$ ). This distribution contrasts with the distribution of Chl- $a$, but is overall in agreement with the distribution of total dissolved nitrogen (TDN) (Table 2).

\subsubsection{Sediment grain size}

According to Udden (1914) and Wentworth (1922), four sediment grain size types are present in the study areas: clay $(<4 \mu \mathrm{m})$, fine silt $(4-16 \mu \mathrm{m})$, coarse silt $(16-64 \mu \mathrm{m})$ and sand $(>64 \mu \mathrm{m})$. The main component is silt, which accounts for almost $70 \%$ of the sediment.

The sediment in aquaculture zone was coarser than that of the other three zones, followed by the sewage outfall zone and the harbor zone, and the finest sediment was found in the outer zone (Fig.2). However, no significant difference was found between the sewage outfall zone, harbor zone and outer zone.

\subsection{Hyperbenthos}

\subsubsection{Univariate measures}

In total, 52 species of hyperbenthos were found in the present study. Crustacea were the most abundant taxon with 18 species (34.6\% of all the species), 


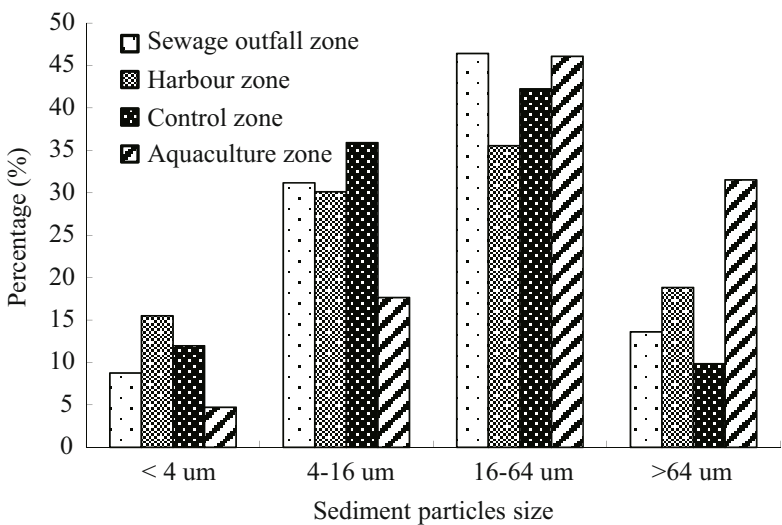

Fig.2 Sediment particles size of the four trawling areas

Table 3 The dominant species and their dominant values ( $Y$ ) $f$ in coastal water of $\mathrm{SB}$

\begin{tabular}{cccc}
\hline Phylum & Species & $f_{i}$ & $Y$ \\
\hline Pisces & Chaeturichthys stigmatias & 0.90 & 0.37 \\
Crustacean & Alpheus japonicus & 1.00 & 0.19 \\
Crustacean & Palaemon gravieri & 0.60 & 0.06 \\
Crustacean & Oratosquilla oratoria & 0.90 & 0.06 \\
Echinoderm & Asterias amurensis & 1.00 & 0.03 \\
Echinoderm & Luidia yezoensis & 0.70 & 0.03 \\
Crustacean & Alpheus distinguendus & 1.00 & 0.02 \\
Mollusca & Neverita didyma & 0.80 & 0.02 \\
Crustacean & Carcinoplax vestitus & 0.60 & 0.02 \\
\hline
\end{tabular}

followed by Echinodermata with 12 species (23.1\%), Mollusca with $10(19.2 \%)$, Pisces with five (9.6\%), Polychaeta with three $(5.8 \%)$ and other groups with four $(7.7 \%)$.

Seven species were identified as dominant species in the research area in accordance with their dominant values $(Y>0.02)$, including four crustaceans, two echinoderms, and one fish (see Table 3). Two other species, Neverita didyma and Carcinoplax vestitus, were also commonly found $(Y=0.018)$.

The spatial distributions of the species number of hyperbenthos present at the 10 trawl stations were variable (Fig.3a). The harbor zone had the greatest species number $(22.7 \pm 7.0$ species $)$, followed by the outer zone ( $19 \pm 4.4$ species), the aquaculture zone (18 species) and finally the sewage outfall zone, which had the lowest species number ( $12 \pm 5.29$ species $)$.

The spatial distribution patterns of the hyperbenthic biomass for the 10 trawl stations followed a similar trend to the total species numbers present in different zones. The greatest biomass occurred in the harbor zone (9 521 $\pm 10118 \mathrm{~g} / \mathrm{ha})$, followed by the outer zone
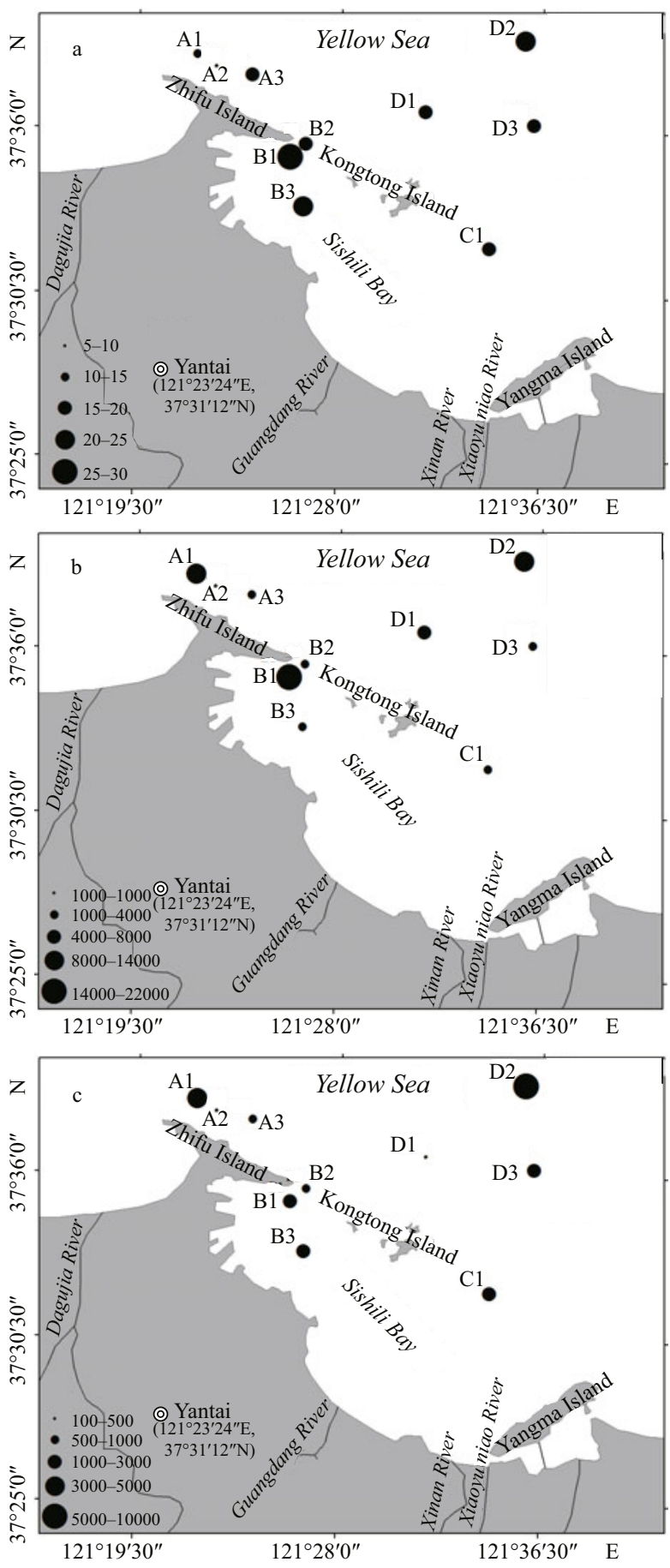

Fig.3 Distributions of the species numbers (a), biomass (g/ ha) (b) and abundances (inds./ha) (c) of hyperbenthos in coastal water of $\mathrm{SB}$

(7 $390 \pm 5676 \mathrm{~g} / \mathrm{ha}$ ), and the sewage outfall zone (4 $551 \pm 5824 \mathrm{~g} / \mathrm{ha}$ ), with the lowest biomass found in the aquaculture zone (3995 g/ha). The average biomass of the hyperbenthos at the four zones was $6838 \pm 6526 \mathrm{~g} /$ ha (Fig.3b).

Total abundances from the study areas showed a different trend to the biomass data. The outer zone 


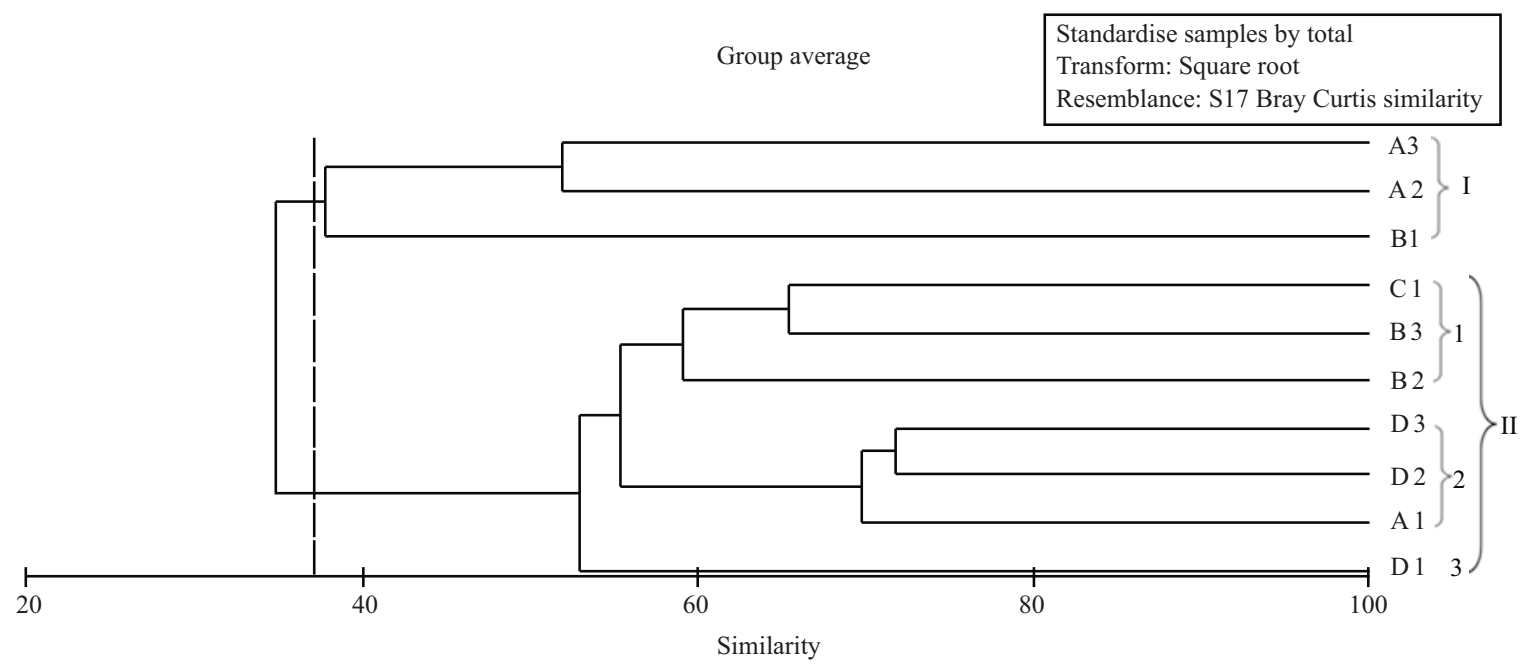

Fig.4 Dendrogram of the similarity of hyperbenthic structures among the 10 stations in coastal waters of SB

Using the group-average linking on Bray-Curtis species similarities calculated on the standardized samples by total and square root transformations of abundance data. Two groups were defined at arbitrary similarity level 38\%.

Table 4 Biodiversity indices of hyperbenthos in coastal water of SB

\begin{tabular}{ccccc}
\hline Areas & $d$ & $J^{\prime}$ & $H^{\prime}\left(\log _{\mathrm{e}}\right)$ & $\begin{array}{c}\text { Total number } \\
\text { of species }\end{array}$ \\
\hline Sewage outfall zone & $3.2 \pm 1.1$ & $1.0 \pm 0.0$ & $2.3 \pm 0.5$ & 23 \\
Harbor zone & $5.4 \pm 1.3$ & $1.0 \pm 0.0$ & $3.0 \pm 0.3$ & 40 \\
Aquaculture zone & 4.4 & 1.0 & 2.8 & 18 \\
Outer zone & $4.5 \pm 0.2$ & $1.0 \pm 0.0$ & $2.8 \pm 0.1$ & 30 \\
\hline
\end{tabular}

$d$ : Margalef richness index; $J^{\prime}$ : Evenness index; $H^{\prime}$ : Shannon-Wiener index

had the highest abundance (3 $707 \pm 4993$ ind./ha) followed by the aquaculture zone (2 $697 \mathrm{ind} . / \mathrm{ha}$ ), the

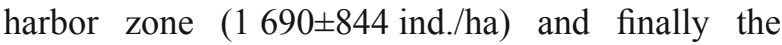
sewage outfall zone (1 $510 \pm 2086$ ind./ha) (Fig.3c). The average abundance was $2342 \pm 2770$ ind./ha.

The Shannon-Wiener index $H^{\prime}$ at eight trawling stations ranged from 2.47 to 3.34 . The harbor zone had the highest value $(3.01 \pm 0.31)$ and the sewage outfall zone the lowest $(2.32 \pm 0.49)$ (Table 4$)$. Only station S1 (sewage outfall zone) had the lowest value of 1.77. The Margalef richness index $d$ and Evenness index $J^{\prime}$ also showed the same pattern.

\subsubsection{Community structure}

A cluster analysis of the hyperbenthos was based on the species and their abundances at the study sites. The results showed that similarity of hyperbenthic assemblages between the stations was low, with similarity values mostly ranging between $50 \%-70 \%$; the highest value was over $70 \%$ for stations D2 and D3 (Fig.4). Based on the similarity values of the hyperbenthic assemblages, the 10 stations were divided into two groups at an arbitrary similarity level of $38 \%$. Group I included three stations, A2, A3, and $\mathrm{B} 1$, with $\mathrm{A} 2$ and $\mathrm{A} 3$ clustered firstly at similarity values of $50 \%$ then grouped with B1. Group II included seven stations, which were further divided into three subgroups, 1, 2, and 3; subgroup 1 included three stations, $\mathrm{B} 3, \mathrm{C} 1$, and $\mathrm{B} 2$, the similarity value of stations $\mathrm{B} 3-\mathrm{C} 1$ was about $65 \%$, then grouped with B2; subgroup 2 included D2, D3 and A1, the highest similarity value $78 \%$ occurred between stations D2 and D3, then grouped with A1; subgroup 3 included only one station, D1, which was separated from the other six stations at a similarity value of about $52 \%$. The MDS plots (Fig.5) show the similar results to the cluster analysis but with some differences.

Further analysis of the abundance data using SIMPER revealed that differences in hyperbenthic species compositions between the 10 stations were responsible for the results of the cluster analysis. In Group I, the average coefficient of the species similarity was $42.5 \%$. The crustacean Alpheus japonicus, the echinoderm Asterias amurensis and the crustacean Trachypenaeus curvirostris were the three dominant species; their contributions to the similarity value were $24.7 \%, 19.5 \%$, and $18.9 \%$, respectively. The other species with contributions to the similarity close to $10 \%$ were Crangon hakodatei $(10.3 \%)$ and Alpheus distinguendus (9.4\%). In Group II, the average coefficient of the species similarity values was up to $57.7 \%$, with two obviously dominant species contributions to the similarity value, namely the fish Chaeturichthys stigmatias (33.8\%) and the 


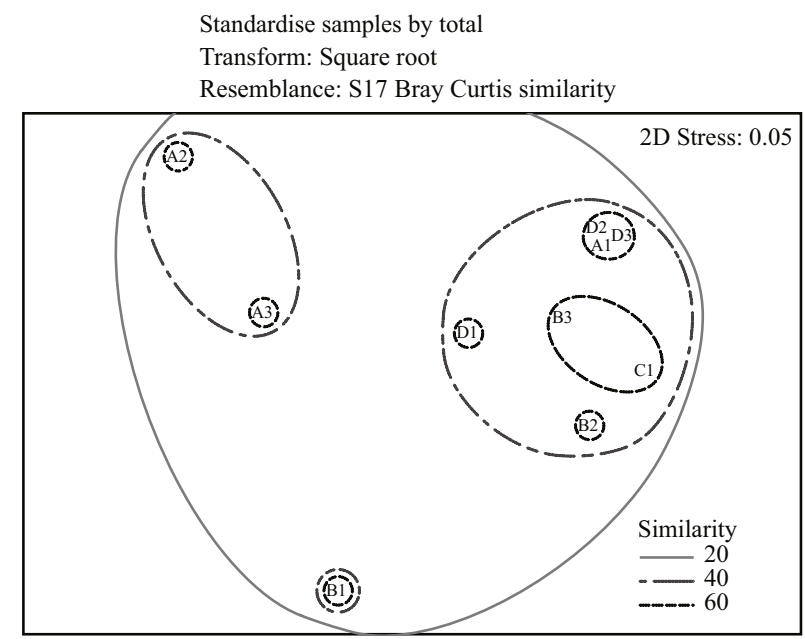

Fig.5 Two-dimensional MDS of the similarity matrix of the 10 stations in coastal water of $\mathrm{SB}$

Using the group-average linking on Bray-Curtis species similarities calculated on the standardized samples by total and the square root transformations of abundance data.

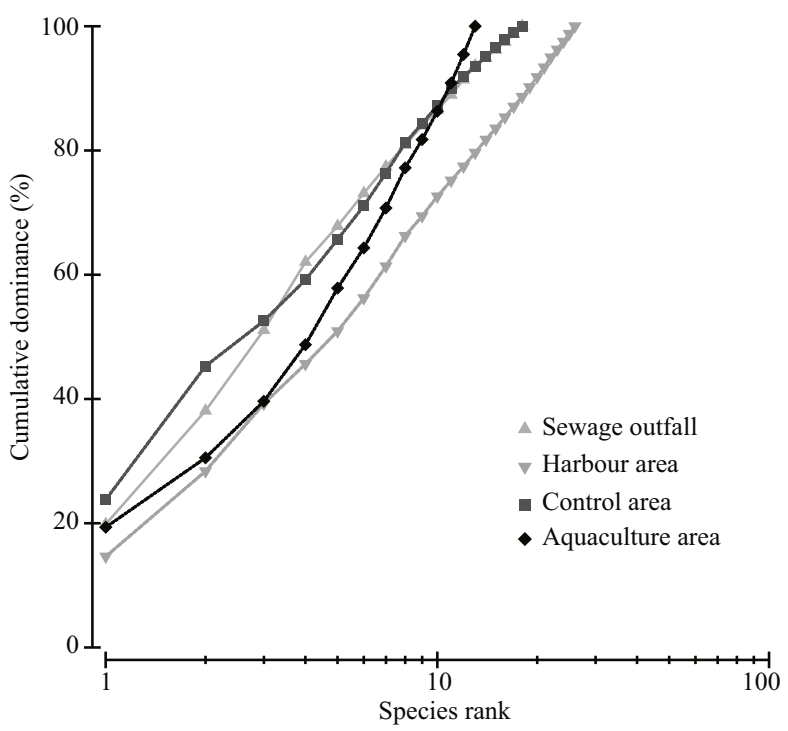

Fig.6 K-dominance curves of hyperbenthos between four zones of SB

crustacean Alpheus japonicus (18.6\%), plus Oratosquilla oratoria $(9.7 \%), A$. distinguendus $(6.0 \%)$, and Neverita didyma (5.2\%), with contributions to a similarity value of over $5.0 \%$. The main reason for the dissimilarity between groups I \& II is C. stigmatias with an average dissimilarity of $10.0 \%$ and a contribution value of $15.3 \%$.

Overall hyperbenthic assemblages in the four zones were not statistically significantly different (ANOSIM, global $R=-0.006, P$ (significance level \%) $>0.05$ ). However, further pairwise tests showed the hyperbenthic assemblages in the sewage outfall zone were significantly different to those in the harbor zone $(R=0.148 P<0.05)$, and the harbor zone was also significantly different to the outer zone $(R=0.111$, $P<0.05)$.

\subsubsection{K-dominance plot and $\mathrm{ABC}$ curves}

The K-dominance plot also showed that there were some differences in the ecological characteristics of the hyperbenthos between the four zones (Fig.6). The cumulative dominant value of the first species was around $20 \%$ in all four zones, where the biggest value occurred in the outer zone, followed by the sewage discharge zone and the aquaculture zone, with the lowest value found in the harbor zone. The first 10 dominant species in the four hyperbenthos communities all had a cumulative dominant value of over $60 \%$, and then showed similar trends for other species.

ABC curves obtained for the four zones are presented in Fig.7. Plots from the 10 stations studied are accompanied by the corresponding $W$ value. Of the 10 stations, six stations (A1-A3, B1, B2, D1) showed positive values of $W$, with abundance more evenly distributed than biomass; and four stations (B3, C1, D2, D3) were considered "perturbed" because of their negative values of $W$. Stations A1, $\mathrm{A} 2, \mathrm{~A} 3$, and B2 were classified as "moderately perturbed" because of the low $W$ values and the existence of crossover between the curves. Only stations B1 and D1 were considered to be "less perturbed".

\subsection{Relationships between hyperbenthic assemblages and environmental variables}

Water quality variables collected at eight stations (A1, A2, A3, B2, B3, C1, D1, D3) were used to analyze relationships with the hyperbenthos structure. The factors included sediment grain size (including the sediment size ranges of $<4 \mu \mathrm{m}, 4-16 \mu \mathrm{m}, 16-$ $64 \mu \mathrm{m},>64 \mu \mathrm{m}$, and median grain size $d(0.5))$, sediment organic matter, nutrients $\left(\mathrm{NO}_{2}-\mathrm{N}, \mathrm{NO}_{3}-\mathrm{N}\right.$, $\mathrm{NH}_{4}-\mathrm{N}, \mathrm{TN}, \mathrm{PO}_{4}-\mathrm{P}, \mathrm{SiO}_{3}-\mathrm{Si}$ ), $\mathrm{pH}$ and $\mathrm{Chl}-a$ in bottom water.

The results showed that the concentrations of $\mathrm{NO}_{3}-\mathrm{N}(R=0.21)$ and Chl- $a(R=0.079)$ had positive correlative relationships with the hyperbenthic community structure, while the other 12 factors had negative correlative relationships, of which the significant factors were $4-16 \mu \mathrm{m}(R=-0.58), d(0.5)$ 

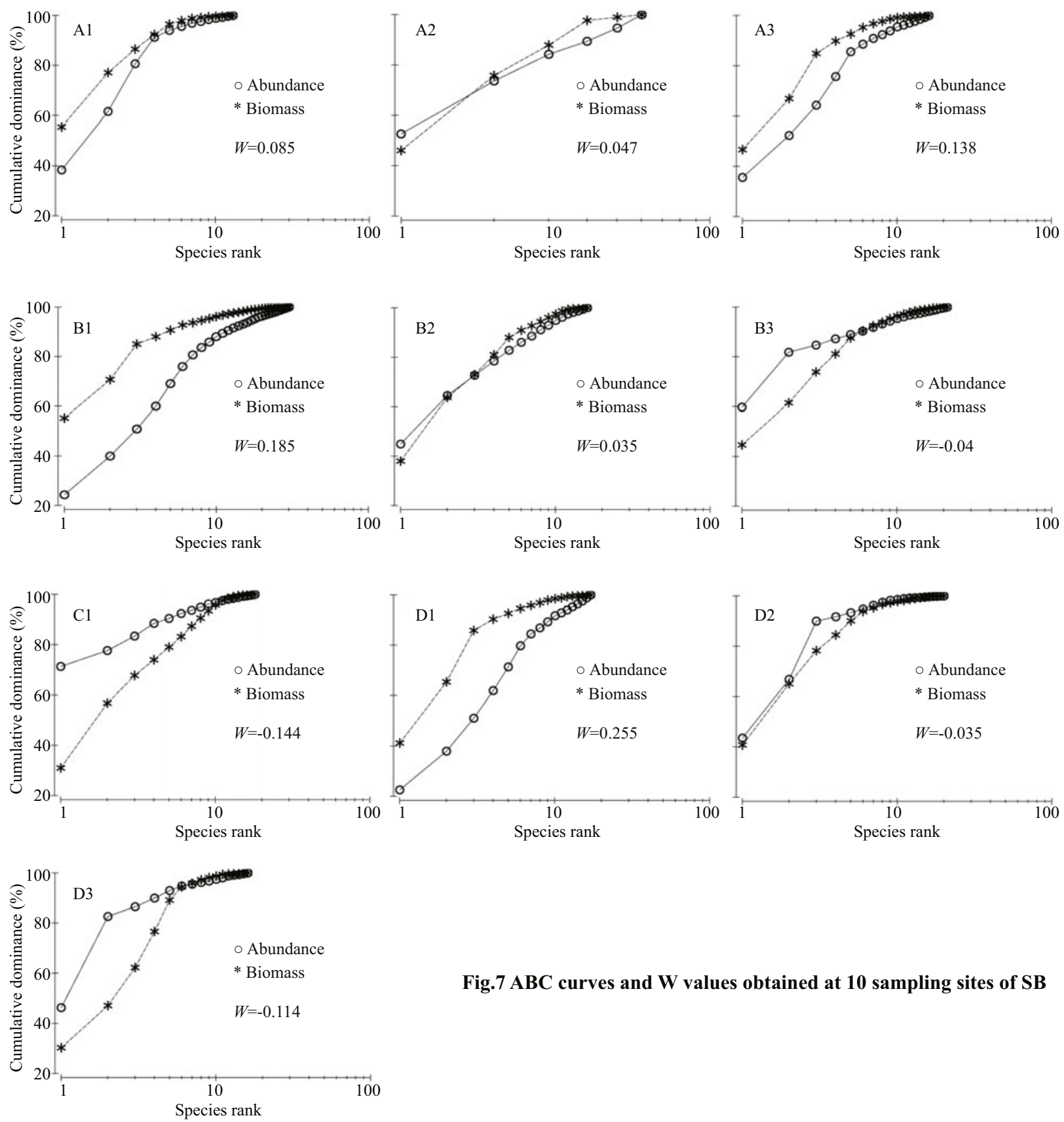

Fig.7 ABC curves and $W$ values obtained at 10 sampling sites of SB

$(R=-0.39)$ and $>64 \mu \mathrm{m}(R=-0.39)$ of sediment size, as well as TN\% concentration $(R=-0.382)$ and TOC \% $(R=-0.38)$ in the sediment.

The result of the BVSTEP (Spearman) analysis showed that a combination of $\mathrm{NO}_{3}-\mathrm{N}$ concentrations and 16-64 $\mu \mathrm{m}$ sediment grain size have the greatest effect on the community structure of hyperbenthos ( $R=0.24)$.

\section{DISCUSSION}

This is the first quantitative study on the hyperbenthos in coastal waters of SB. Previously we surveyed the hyperbenthos in the coastal water of Weihai Port, about $45 \mathrm{~km}$ east of SB, and found very similar results in terms of species composition and dominant species (Han et al., 2011). Other previous surveys (Zhang et al., 2005) focused on species composition, and did not quantify assemblage characteristics such as biomass and abundance. They also used different sampling strategies, thus it is difficult to compare SB with adjacent waters in terms of temporal and spatial changes. Therefore, the quantitative analysis on the distribution of the biomass and abundance of the hyperbenthos in this study 
provide a baseline for further study and assessment of environmental change in this area.

The biomass and abundance of hyperbenthos found at the 10 sampling sites in the four zones were spatially different, but the standard deviations of both abundance and biomass in the four zones were relatively high. This could be due to several factors: the clustered distribution pattern of hyperbenthos, food sources, small difference and the low number of samples obtained during this survey. The results of the CLUSTER and MDS analysis show that the structures of the hyperbenthic communities in four zones of SB are relatively different. The low similarity values between them are due to habitat variability, which in turn may be due to direct or indirect ecological effects of human activities. The MDS plots did not coincide exactly with the results of the cluster analysis, especially for the three stations A1, B1, and $\mathrm{C} 1$. These differences could be due to the influence of physical processes including tides, wind, and water discharge rather than anthropogenic influences, or the combined effects of multiple variables. Elsewhere in China, in some uniform habitats and homogeneous regions, the structure of the macrobenthic communities are very similar to each other, with higher values of Bray-Curtis similarity (Li et al., 2007) in contrast to this study.

Dominance plots can be computed for abundance, biomass, percentage cover or other biotic measures representing the quantity of each taxon, which also can be used to indicate the quality of habitat (Clarke and Warwick, 2001). In this study, the curve of harbor zone was the lowest line indicating that diversity was highest at this site. The curves for the other four zones were elevated, which suggests that the hyperbenthic habitats in SB were polluted and that the assemblages had suffered from some kind of disturbance.

Coastal marine benthic communities are threatened by anthropogenic activities, and the rate of habitat degradation is alarming at present (Grey, 1997; Snelgrove et al., 1997). Several studies also proved that anthropogenic activities and environmental variables influence the spatial and temporal distributions of macrofaunal abundance and biomass (DelValls et al., 1998; Magni et al., 2005, 2006). In the present study, analysis of $\mathrm{ABC}$ curves indicates that the hyperbenthos of SB has been disturbed by human activities. The assemblages at eight out of 10 stations can be classified from "moderately perturbed" to "perturbed". Important environmental variables include current direction and speed, sediment structure and the diversity of the epibenthic habitat (De Broye et al., 2001). Pollution also causes changes in community composition with drastic reductions in diversity (Ferrara et al., 1991; Snelgrove, 1998). Magni et al. (2005) concluded that an excess of sedimentary organic matter might strongly affect the composition, structure and distribution of macrofaunal communities of a lagoon. Strong tidal currents have major effects on the distribution and stability of sediment and consequently the structure of benthic communities (Dauvin et al., 2000). Along the periphery of the Bay, tidal currents move mainly back and forth in a northwest-southeast direction, thus pollutants and nutrients are mainly moved alongshore parallel to coasts. However, the tidal residual currents along Zhifu Island are known to be southeastward, which means that pollutants are also predominantly transported southeastwards. Meanwhile in the inner bay, as a result of weak tidal currents, water exchange between Sishili Bay and its surroundings is limited. Therefore, the prevailing southeasterly wind can favor the transport pollutants and nutrients into the harbor zone (B1, B2, B3) and their subsequent accumulation, resulting in lower water quality. Because of the relatively shallow water in SB (from $8.5 \mathrm{~m}$ to $18.7 \mathrm{~m}$ in depth), the tidal currents might also have an impact on the sediment.

Smith et al. (2000) predicted that at least five anthropogenic processes could affect the biodiversity and diversity across the sediment-water interface: global climate change, coastal-zone eutrophication, species introductions, mariculture, and bottom fishing. Sewage outfalls increasingly result in coastal eutrophication, which can lead to a striking increase of hypoxia and anoxia in coastal bottom waters (Diaz and Rosenberg, 1995). Under these oxygen-stressed conditions, the linkages between pelagic and benthic fauna are weakened; most benthic species will not release their larvae into an oxygen depleted water column, and some of them will die or move elsewhere because of intolerance of low oxygen conditions (Smith et al., 2000), resulting in reduced biodiversity. This coincides with our findings, e.g. the sewage outfall zone has the lowest value of species number, abundance and Shannon-Wiener index $H^{\prime}$ among the four zones.

Bivalve aquaculture has multiple effects on local marine ecosystems, influencing both physical and biological factors, including local benthic effects (bio-deposition and enrichment, accumulation of shell litter, debris), water column effects and 
interactions with the benthic environment (altered current and flushing; water quality; nutrient cycling; suspended particulate matter depletion) (Forrest et al., 2009), all of which could directly or indirectly affect benthic assemblages. One of the most obvious effects of mariculture on benthic habitats is organic enrichment (Weston, 1990), which has effects similar to those resulting from organic loading and low oxygen stress induced by coastal eutrophication (Smith et al., 2000). In the present study, the most important effects on benthic habitats in the harbor area are likely to be caused by recurrent bottom disturbances due to waterway dredging, which are likely to alter benthic biodiversity dramatically (Smith et al., 2000).

What are the consequences for other organisms if the hyperbenthos community has been disturbed? Macrobenthic invertebrates are a very important group in benthic ecosystems, exerting a structuring influence on the habitat. Some key species, especially some deposit feeders, can modify the physical and chemical conditions of sediment by their activities such as burrowing and feeding (Lohrer et al., 2004). The mixing and displacement of sediment by benthic macrofauna can affect rates of organic matter degradation and carbon burial (Lohrer et al., 2005). There are many linkages across the sediment-water interface (SWI) between biodiversity and community stability. As to the role of hyperbenthos in linking biodiversity above and below the SWI, this still requires further investigation (Mees and Jones, 1997; Dauvin et al., 2000). Austen et al. (2002) proposed the hypothesis that changes in hyperbenthic communities may affect both above and below SWI communities. In most areas, the diversity above the SWI can potentially affect the diversity below the SWI through productivity, predation, and associated sediment disturbance (bioturbation), and recruitment processes (Snelgrove et al., 2000).

In the present study, we found that the spatial distribution pattern, species richness, and community composition of hyperbenthos in the four zones were different to a certain extent. Further analysis of ABC curves suggests that the assemblages suffered from different anthropogenic activities. It is currently difficult to define the contribution of different kinds of anthropogenic activities to the disturbance of the hyperbenthos because of insufficient data and the complexity of the ecosystem. However, the present study provides important background information on hyperbenthos in this area, and highlights the potential impact of human activities in the coastal zone on benthic assemblages. We recommended that this type of study be repeated on a more frequent time scale and at higher spatial resolutions to provide indications of the changing environmental conditions of SB.

\section{References}

Austen M C, Lambshead P T D, Hutchings P A et al. 2002. Biodiversity links above and below the marine sedimentwater interface that may influence community stability. Biodivers. Conserv., 11: 113-136.

Brandt A. 1993. Composition, abundance, and diversity of peracarid crustaceans on a transect of the Kolbeinsey Ridge, north of Iceland. Polar Biol., 13: 565-576.

Brandt A. 1995. Peracarid fauna (Crustacea, Malacostraca) of the Northeast Water Polynya off Greenland: documenting close benthic-pelagic coupling in the Westwind Trough. Mar. Ecol. Prog. Ser., 121: 39-51.

Chen Y Q, Xu Z L. 1995. An ecological study on zooplankton in plume front zone of Changjiang (Yangtze) River Estuarine Area I: biomass distribution of dominant species. Journal of Fishery Sciences of China, 2(1): 4963. (in Chinese with English abstract)

Clarke K R, Gorley R N. 2001. Primer V5: User Manual/ Tutorial. Plymouth. PRIMER-E.

Clarke K R, Warwick R M. 2001. Changes in marine communities: an approach to statistical analysis and interpretation. 2nd edition, PRIMER-E: Plymouth. p.8-6.

Dauvin J C, Vallet C, Mouny P et al. 2000. Main characteristics of boundary layer macrofauna in the English Channel. Hydrobiogia, 426: 139-156.

De Broyer C, Scailteur Y, Chapelle G et al. 2001. Diversity of epibenthic habitats of Gammaridean amphipods in the eastern Weddell Sea. Polar Biol., 24: 744-753.

DelValls T A, Conradi M, Garcia-Adiego E et al. 1998. Analysis of macrobenthic community structure in relation to different environmental sources of contamination in two littoral ecosystems from the Gulf of Cádiz (SW Spain). Hydrobiologia, 385: 59-70.

Diaz R J, Rosenberg R. 1995. Marine benthic hypoxia: a review of its ecological effects and the behavioral responses of benthic macrofauna. Oceanogr. Mar. Biol., 33: 245-303.

Dong Z, Liu D, Keesing J K. 2010. Jellyfish blooms in China: dominant species, causes and consequences. Mar. Pollut. Bull., 60: 954-963.

Ferrara S P, Swartz R C, Cole F A, Schults D W. 1991. Temporal changes in the benthos along a pollution gradient: discriminating the effects of natural phenomena from sewage-industrial wastewater effects. Estuar. Coast. Shelf Science, 33: 383-487.

Forrest B M, Keeley N B, Hopkins G A et al. 2009. Bivalve aquaculture in estuaries: review and synthesis of oyster cultivation effects. Aquaculture, 298: 1-5.

Grey J S. 1997. Marine biodiversity: pattern, threats and conservation needs. Biodivers. Conserv., 7: 153-175. 
Han Q X, Li B, Han Q Y et al. 2011. Preliminary study of the impact of fishery trawling on epifauna community in the coastal water of Weihai Port. Marine Science Bulletin, 30(2): 121-126. (in Chinese with English abstract)

Ji L, Wang R, Liu C et al. 2003. Environmental monitoring and contrast evaluation on Yantai marine dumping site. Marine Science Bulletin, 22(2): 53-59. (in Chinese with English abstract)

Li X, Li B, Wang H et al. 2007. Macrobenthic community characters of Zhubi Reef, Nansha Islands, South China Sea. Acta Zool. Sin., 53(1): 83-94. (in Chinese with English abstract)

Liu D, Keesing J K, Xing Q, Shi P. 2009. World's largest macroalgal bloom caused by expansion of seaweed aquaculture in China. Mar. Pollut. Bull., 58: 888-895.

Liu X, Liu Y, Zhao R et al. 2010. Analysis of the features and dynamic changes of biological community structure in the Yantai marine dumping site. Marine Science Bulletin, 29(4): 396-401. (in Chinese with English abstract)

Liu Y, Liu X, Xing H et al. 2006. Analysis of the water quality in the sea area of Sishili Bay of Yantai in 2003. Transactions of Oceanology and Limnology, 3: 93-97. (in Chinese with English abstract)

Lohrer A M, Thrush S F, Gibbs M M. 2004. Bioturbator enhance ecosystem function through complex biogechemical interactions. Nature, 43: 1 092-1 095.

Lohrer A M, Thrush S F, Hunt L et al. 2005. Rapid reworking of subtidal sediments by burrowing spatangoid urchins. $J$. Exp. Mar. Biol. Ecol., 321: 155-169.

Lu L. 2005. The relationship between soft-bottom macrobenthic communities and environmental variables in Singaporean waters. Mar. Pollut. Bull., 51: 1 034-1 040.

Magni P, Como S, Montani S et al. 2006. Interlinked temporal changes in environmental conditions, chemical characteristics of sediments and macrofaunal assemblages in an estuarine intertidal sandflat (Seto Inland Sea, Japan). Mar. Biol., 149: 1 185-1 197.

Magni P, Micheletti S, Casu D et al. 2005. Relationships between chemical characteristics of sediments and macrofaunal communities in the Cabras lagoon (Western Mediterranean, Italy). Hydrobiologia, 550: 105-119.

McGlathery K J, Sundback K, Anderson I C. 2007. Eutrophication in shallow coastal bays and lagoons: the role of plants in the coastal filter. Mar. Ecol. Prog. Ser., 348: $1-18$.

Mees J, Jones M B. 1997. The hyperbenthos. Oceanogr. Mar. Biol., 35: 221-255.

Pearson T H, Rosenberg R. 1978. Macrobenthic succession in relation to organic enrichment and pollution of the marine environment. Oceanogr. Mar. Biol., 16: 229-311.

San Vicente C, Castelló J, Corbera J et al. 2007. Biodiversity and structure of the suprebenthic assemblages from South Shetland Islands and Bransfield Strait, Southern Ocean. Polar. Biol., 30: 477-486.

San Vicente C, Ramos A, Gimeno A et al. 1997. Suprabenthic assemblages from South Shetland Islands and Bransfield Strait (Antarctica): preliminary observations on faunistical composition, bathymetric and near-bottom distribution. Polar Biol., 18: 415-422.

Smith C R, Austen M C, Boucher G et al. 2000. Global change and biodiversity of marine sediments: impacts and linkages across the sediment-water interface. BioScience, 50: 1 108-1 120.

Snelgrove P V R. 1998. The biodiversity of macrofaunal organisms in marine sediments. Biodivers. Conserv., 7: 1 123-1 132.

Snelgrove P V R, Austen M C, Bouche R G et al. 2000. Sediments-up and water column-down: linking biodiversity above and below the marine sediment-water interface. BioScience, 50: 1 076-1 088.

Snelgrove P V R, Blackburn T H, Hutchings P A et al. 1997. The importance of marine sediment biodiversity in ecosystem processes. Ambio, 26: 578-583.

Tang Q. 2004. Study on Ecosystem Dynamics in Coastal Ocean. III, Atlas of the Resources and Environment in the East China Sea and the Yellow Sea Ecosystem. Science Press, Beijing, China. 398 p. (in Chinese)

Udden J A. 1914. Mechanical composition of clastic sediments. Bull. Geol. Soc. Am., 25: 655-744.

Wang X, Xu Z, Zhou X. 1995. Animal survey in Yantai inshores. Chinese Journal of Ecology, 14(1): 6-10. (in Chinese)

Wentworth C K. 1922. A scale of grade and class terms for clastic sediments. J. Geol., 30: 377-392.

Weston D P. 1990. Quantitative examination of macrobenthic community changes along an organic enrichment gradient. Mar. Ecol. Prog. Ser., 61: 233-244.

Wu Y, Zhang B. 1994. Ecological characters of macrobenthos in Zhifu Bay, Yantai. Marine Environmental Science, 13(3): 1-6. (in Chinese)

Ye J, Cai L, Huang R et al. 2010. Species composition of trawling mollusk in Beibu Gulf and its environmental effect. Marine Science Bulletin, 29 (6): 617-622. (in Chinese with English abstract)

Zhang F, Zhang Y, Zhang X et al. 2005. Diversity of benthic boundary layer fauna in a section of the Yellow Sea in summer. Biodiversity Science, 1: 1-11. (in Chinese with English abstract)

Zhang R, Dong Y. 1990. Analysis of conditions of natural environment in sea areas for pollutant discharge and the study on pathways of pollutant transport in Yantai. Coastal Engineering, 6(2): 35-44. (in Chinese with English abstract) 